\title{
Özgün araştırma makalesi Çocuklarda tedavi edilmemiş diş çürüklerinin PUFA indeksi ile değerlendirilmesi
}

\author{
Nagehan Aktaş, ${ }^{1 *}$ Neşe Akal, ${ }^{1}$ Yasemin Akın, ${ }^{1}$ \\ Azime İlknur Moğulkoç² \\ ${ }^{1}$ Pedodonti Anabilim Dalı, Diş Hekimliği Fakültesi, Gazi \\ Üniversitesi, Ankara, ${ }^{2}$ Serbest diş hekimi, İzmir, Türkiye
}

\begin{abstract}
ÖZET
AmAÇ: Diş çürüğü özellikle gelişmekte olan ülkelerde ciddi bir sağlık problemi olarak karşımıza çıkmaya devam etmektedir. Tedavi edilmemiş diş çürüklerinin yol açtığı apse, ülserasyon ve fistül gibi komplikasyonların prevalansını araştıran sınırlı sayıda araştırma bulunmaktadır. Bu çalışmanın amacı, bir grup çocukta tedavi edilmemiş diş çürüklerinin klinik sonuçlarının prevalansının araştırılmasıdır.
\end{abstract}

GeREÇ VE YönTEM: Çalışma 1-31 Mart 2012 tarihleri arasında Gazi Üniversitesi Diş Hekimliği Fakültesi Pedodonti Anabilim Dalı Kliniğinde yaşları 5-12 arası olan 1200 çocuk üzerinde yürütüldü. Daimi ve süt dişlerinde diş çürükleri DMFT/dmft ve PUFA/pufa indeksleri ile skorlandı (D/d: çürük, M/m: kayıp, F/f: dolgulu diş, P/p: pulpayı içeren çürük lezyonu, U/u: kök parçalarından dolayı mukozanın ülserasyonu, F/f: fistül, A/a: apse).

BulgulaR: Çocuklarda DMFT indeksi $2.34 \pm 1.37 \mathrm{ve} \mathrm{dmft}$ indeksi $4.25 \pm 3.46$ olarak bulundu. Daimi ve süt dişleri için PUFA/pufa prevalansı sırasıyla $\% 2.30$ ve $\% 22.25$ olarak belirlendi. Hem süt hem daimi dişlerde en yüksek skoru pulpayı içeren diş çürüğü oluşturdu (daimi dişlerde $\% 1.67$ ve süt dişlerinde \%11.24). Bunu apse ve fistülizasyon izledi.

Sonuç: Seçilen popülasyonda tedavi edilmemiş süt dişi çürüklerinin ve yumuşak dokudaki klinik sonuçlarının prevalansı yüksek bulundu. PUFA/pufa indeksi diş çürüklerini değerlendirmek amacıyla var olan çürük indekslerini tamamlayıcı bir epidemiyolojik araç olarak görülmektedir.

Anahtar Kelimeler: Apse; çocuk; diş çürükleri; DMF indeksleri; fistül

Kaynak Göstermek İçin: Aktaş N, Akal N, Akın Y, Moğulkoç Ai. Çocuklarda tedavi edilmemiş diş çürüklerinin PUFA indeksi ile değerlendirilmesi. Acta Odontol Turc 2018;35(1):23-8

ЕрітӧR: Zeynep Ökte, Ankara Üniversitesi, Ankara, Türkiye

YAYıN HAKKI: (c) 2018 Aktaş ve ark. Bu eserin yayın hakkı

Makale gönderiliş tarihi: 18 Șubat 2016; Yayına kabul tarihi: 01 Haziran 2017 *iletişim: Dr. Nagehan Aktaş, Pedodonti Anabilim Dalı, Diş Hekimliği Fakültesi, Gazi Üniversitesi, Bişkek Caddesi, 82.Sokak C Blok 5. kat, 06510, Emek Ankara, Türkiye; E-posta: nagehanduygu@gmail.com
Creative Commons Attribution License ile ruhsatlandırılmıştır. Sınırsız kullanım, dağıtım ve her türlü ortamda çoğaltım, yazarlar ve kaynağın belirtilmesi kaydıyla serbesttir.

[Abstract in English is at the end of the manuscript]

\section{Giriş}

Diş çürüğü, önleyici ve tedavi edici uygulamalardaki gelişmelere rağmen en sık görülen çocukluk çağı hastalığı olmaya devam etmektedir., ${ }^{1,2}$ Özellikle düşük ve orta gelirli ülkelerde karyojenik gıda tüketiminin fazla olması, günlük ağız sağlığı bakımının yapılmaması, düzenli diş hekimi kontrolünün eksikliği ile diş çürüğü ciddi bir problem olarak karşımıza çıkmaktadır. ${ }^{3,4}$ Türkiye genelinde yapılan bir araştırmada DMFT/dmft'nin 5 yaş grubu çocuklarda 3.7 olduğu, 12 yaş grubunda 1.9 ve 15 yaş grubunda 2.3 olduğu bildirilmiştir. Aynı çalışmada 5 yaş grubundaki çocukların yalnızca \%30.2'sinde çürük olmadığı görülmektedir. ${ }^{5}$

Diş çürükleri tedavi edilmediklerinde ağrı ve enfeksiyon gibi bazı komplikasyonlara yol açabilir. Çocuklarda tedavi edilmemiş diş çürüklerinin ortaya çıkardığı problemler çeşitli çalışmalarda bildirilmiştir. ${ }^{6-14}$ Üst ön bölge dişlerinin erken kaybında ilk ortaya çıkan sorun dil-diş ünsüzlerinin telaffuz edilmemesine bağlı konuşma bozukluğudur. Erken diş kayıpları ayrıca azalmış kas tonusuna, anormal dil alışkanlıklarına ve malokluzyona sebep olmaktadır. ${ }^{15,16}$ Diş çürüğü sebebiyle ağrı ve çiğnemede güçlük gibi problemler, çocuklarda yiyecek alımının ve uyku süresinin azalmasına bağlı olarak büyüme ve gelişimi etkilemektedir. ${ }^{17,18}$ Renklenmiş ve çürük dişlere bağlı olarak öz saygı eksikliği, iletişim problemleri ve okuldaki devamsızlık sebebiyle üretkenlik, öğrenme süreci ve eğitim performansı etkilenmektedir. ${ }^{7}$ Yine tedavi edilmeyen süt dişlerinde apikal lezyon gelişirse alttaki daimi diş germinde 'Turner hipoplazisi' gelişme riski fazladır., ${ }^{6,19}$ Daha ciddi vakalarda ise tedavi edilmeyen diş çürüklerinin sebep olduğu enfeksiyöz komplikasyonlar, çocukların hospitalize edilmesine sebep olmaktadır. Bunun yanında tedavi edilmeyen diş çürüklerinin tedavi masrafları nedeniyle ailelerini de maddi ve manevi açıdan olumsuz etkileyerek yaşam kalitesini ciddi şekilde düşürdüğü de görülmektedir. ${ }^{6,7}$

Dünya genelinde son 70 yıldır diş çürüğü ile ilgili 


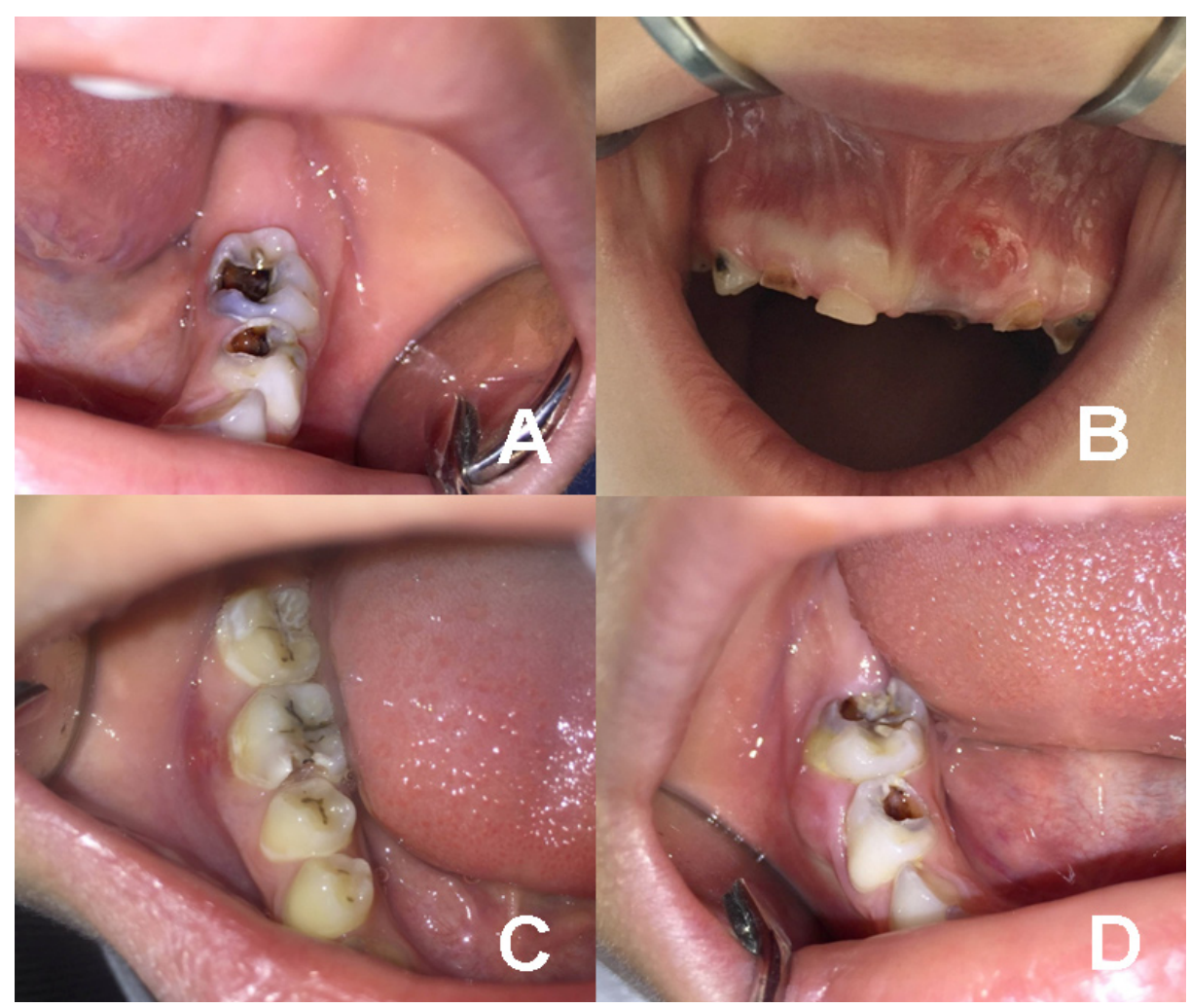

Resim 1. Kullanılan indekse ait olgu örnekleri; (A) P/p: 75 numaralı dişe ait pulpa ile ilişkili çürüğün klinik olarak görünümü, (B) U/u: 61 numaralı dişe ait ülserasyonun klinik olarak görünümü, (C) F/f: 46 numaralı dişe ait fistül oluşumunun klinik olarak görünümü, (D) A/a: 85 numaralı dişe ait apse oluşumunun klinik olarak görünümü

veriler DMFT/dmft indeksi ile belirlenmektedir. Bu indeks çürük ve kayıp dişler ile ilgili bilgi sağlarken, tedavi edilmemiş diş çürüklerinin pulpayla ilişkili olması ya da diş apsesine sebep olup olmadığı gibi klinik sonuçları ile ilgili bilgi sağlamada yetersizdir. Pulpayı içeren derin çürük kaviteleri 'dentin çürüğü' kodu ile belirtilmektedir; fakat pulpal içerikten bahsedilmemektedir. 'Diş çekimi endikedir' kodu altında çürük lezyonların ciddiyeti bildirilmektedir; fakat bu kod çekimin sebebini (travma ya da ortodontik amaçla) vermemektedir. ${ }^{20,21} \mathrm{Bu}$ nedenle 2010 yılında Monse ve ark. ${ }^{14}$ tarafından tedavi edilmemiş diş çürükleri sonucu ortaya çıkan ağız bulgularını değerlendiren PUFA/pufa indeksi geliştirilmiştir. Bu indeksin kullanımı Dünya Sağlık Örgütü (DSÖ) tarafından da desteklenmiştir. DSÖ'nün 2013 yılında yayınladığı 'Ağız Sağlığı Araştırmaları Temel Yöntemler' rehberinde çocuklar için daha önce önerilen forma ilave olarak ağız içi mukozasında lezyon ve acil müdahale intiyacı başlıkları altında veri toplanması da önerilmektedir. ${ }^{20}$ Ayrıca çocukların ağız sağlığını değerlendirmelerinde diş hekimine en son gitme nedeni, son 1 yıl içerisinde ısırmada ve çiğnemede güçlük, sözcüklerin telaffuzunda problem, dişlerin görüntüsünden utanma, dişler ve ağızdaki sorunlar nedeniyle gerginlik hissi ve dişler nedeni ile gülmekten kaçınma gibi sorular da bu forma eklenmiştir. ${ }^{20}$

Bu çalışmada, tedavi amacıyla kliniğimize başvuran bir grup çocukta tedavi edilmemiş diş çürüklerinin prevalansı ve bununla ilişkili olarak ortaya çıkan ağız içi bulgularının PUFA/pufa indeksi ile değerlendirilmesi amaçlanmıştır.

\section{Gereç Ve Yöntem}

Bu çalışma, 1-31 Mart 2012 tarihleri arasında Gazi Üniversitesi Diş Hekimliği Fakültesi Pedodonti Anabilim Dalı Kliniğine muayene için başvuran, yaşları 5 ile 12 arasında olan rastgele seçilmiş 1200 çocuk hasta üzerinde yürütüldü. Çalışma, Ankara Üniversitesi Diş Hekimliği Fakültesi etik kurul onayı ile gerçekleştirildi (Protokol no: 36290600/06). Çocuklar DMFT/dmft ve PUFA/pufa indeksleri ile değerlendirildi.

PUFA/pufa indeksinin kodları pulpayı içeren diş çürüğü, kök fragmanlarından dolayı yumuşak dokularda meydana gelen ülserasyon, fistül ve appse varlığına göre kayıt edilmektedir. Süt ve daimi dentisyon için PUFA/pufa indeksi ayrı ayrı hesaplanmaktadır. Büyük harfler (PUFA) daimi dentisyonu, küçük harfler (pufa) süt dentisyonunu göstermektedir. PUFA/pufa kodlarının tanımlanması: ${ }^{14}$

P/p: Pulpa ile ilişkili çürük, pulpa odasının gözle görülebilir şekilde açıldığı veya koronal diş yapısının çürük sebebiyle tamamen kaybolduğu ve sadece kök ve/veya kök parçalarının kaldığı durumlarda kayıt edilir (Resim 1).

U/u: Ülserasyon, çürük sebebiyle aşırı harap olmuş 
Tablo 1. Yaş gruplarına göre daimi dentisyondaki PUFA kodlarının ve süt dentisyondaki pufa kodlarının dağııımı

\begin{tabular}{|c|c|c|c|c|}
\hline & 5 yaş $(n)$ & 6-7 yaş (n) & $8-10$ yaş $(n)$ & $11-12$ yaş (n) \\
\hline $\mathbf{P}$ & - & 0 & 6 & 14 \\
\hline $\mathbf{U}$ & - & 0 & 0 & 0 \\
\hline $\mathbf{F}$ & - & 0 & 1 & 2 \\
\hline A & - & 0 & 1 & 2 \\
\hline p & 43 & 87 & 31 & 13 \\
\hline u & 4 & 14 & 5 & 1 \\
\hline f & 6 & 13 & 6 & 2 \\
\hline a & 17 & 17 & 7 & 1 \\
\hline
\end{tabular}

Büyük harfler daimi dentisyonu, küçük harfler süt dentisyonu göstermektedir; P/p: Pulpa ile ilişkili çürük; U/u: Ülserasyon; F/f: Fistül; A/a: Apse. SS: standart sapma

dişlerin keskin kenarlarının ve/veya kök parçalarının yer değiştirmesine bağlı yumuşak dokularda meydana gelen travmalar kayıt edilir (Resim 1).

F/f: Fistül, pulpayla ilişkili çürük dişten iltihabın fistül yoluyla ağız boşluğuna açıldığı durumlarda kayıt edilir (Resim 1).

A/a: Apse, pulpayla ilişkili çürük dişten kaynaklanan iltihap içeren şişliğin görüldüğü durumlarda kayıt edilir (Resim 1).

Çalışma öncesinde, değerlendirmeyi yapacak olan üç diş hekimine PUFA/pufa kodları ile ilgili teorik eğitim verildi ve 20 hasta üzerinde kalibre edildi. Hekimler arasında klinik değerlendirme için tekrar edilebilirlik Kappa istatistiği ile değerlendirildi ve iyi Kappa değeri (0.9) bulundu.

Muayene edilecek tüm çocukların işlem öncesinde dişleri fırçalatıldı. Supine pozisyonda yatan çocuklarda gün ışığı altında DMFT/dmft indeksi için ağız aynası ve DSÖ'nün önerdiği Community Periodontal Index (CPI) sondu kullanılarak, PUFA/pufa indeksi için ise yalnızca ağız aynası kullanılarak değerlendirme yapıldı. PUFA/ pufa indeksinin değerlendirilmesi sırasında herhangi bir el aleti kullanılmadı. Diş yüzeyindeki debris pamuk peletle uzaklaştırıldı, diş çürüğünün pulpaya ulaşıp ulaşmadığı sondlama ile kontrol edilmedi. Tedavi edilmemiş diş çürükleriyle ilgili olmayan diğer dokulardaki lezyonlar kayıt altına alınmadı. Diş başına yalnızca bir skor verildi. Eğer odontojenik enfeksiyonun varlığı hakkında şüphe varsa, temel skor $(\mathrm{P} / \mathrm{p})$ verildi. PUFA/pufa prevalansı, Monse ve ark. ${ }^{14}$ tarafından yapılan çalışmada bildirildiği şekilde her bir hasta için aşağıdaki formüle göre hesaplandı:

$$
\frac{\text { PUFA }+ \text { pufa }}{D+d} \times 100
$$

Verilerin analizi SPSS 11.5 (SPSS Inc. Chicago, IL,
ABD) paket programında yapıldı. İstatistiksel farklılık ki-kare testi ile belirlendi. Tanımlayıcı istatistikler ortalama \pm standart sapma şeklinde gösterildi. Aksi belirtilmedikçe $p<0.05$ için sonuçlar istatistiksel olarak anlamlı kabul edildi.

\section{BULGULAR}

Beş ile on-iki yaş arasındaki 559 kız, 641 erkek olmak üzere 1200 çocuk hasta üzerinde yürütülen çalışmada bütün olarak bakıldığında DMFT indeksi $2.34 \pm 1.37$ iken, dmft indeksi ise $4.25 \pm 3.46$ olarak bulundu. Daimi ve süt dişleri için PUFA/pufa prevalansı sırasıyla \%2.30 ve \%22.25 olarak belirlendi. PUFA/pufa prevalansının erkeklerde (\%51.9) kızlardan (\%48.1) daha yükek olduğu gözlendi. Süt dişlerinde en fazla etkilenen dişin mandibular sol ikinci molar, daimi dişlerde ise maksiller sol birinci molar ve mandibular sağ birinci molar dişler olduğu saptandı. Yaş gruplarına göre PUFA/ pufa kodlarının ve prevalanslarının dağılımı Tablo 1 ve 2'de gösterilmektedir. PUFA/pufa kodları arasında istatistiksel olarak anlamlı bir fark bulunmadı ( $p>0.05)$.

Daimi dişlerde en sık rastlanan PUFA indeks parametresi \%1.67 ile pulpayı içeren diş çürüğü $(P)$, en az rastlanan parametre ise ülserasyon (Ü) oldu. Süt dişlerinde ise en sık rastlanan pufa indeks parametresi \%11.24 ile pulpayı içeren diş çürüğü (p), en az rastlanan parametre ise ülserasyon (ü) ve apse (a) oldu. Yaş gruplarına göre süt dişleri için pufa kodlarının prevalansının dağılımı incelendiğinde 6-7 yaş, 8-10 yaş ve 11-12 yaş grubunda en yüksek prevalans pulpa ile ilişkili diş çürüğünde ( $p$ ) gözlenirken; 5 yaş grubundaki çocuklarda ise en yüksek prevalans fistül (f) olan dişlerde izlendi. Yaş gruplarına göre daimi dişler için PUFA kodlarının prevalansının dağılımı incelendiğinde 8-10 yaş grubunda en yüksek prevalans pulpa ile iliş̧ili diş çürüğünde $(P)$ gözlenirken; 11-12 yaş grubundaki çocuklarda ise en yüksek prevalans apse (A) olan dişlerde izlendi.

Süt dişlerindeki pufa prevalansının (\%22.25) yaş grubuna bağlı olarak daimi dişlerin PUFA prevalansından 
Tablo 2. Yaş gruplarına göre PUFA/pufa kodları prevalansının dağılımı (\%)

\begin{tabular}{lcccc}
\hline & $\mathbf{5}$ yaş & $\mathbf{6 - 7}$ yaş & $\mathbf{8 - 1 0}$ yaş & $\mathbf{1 1 - 1 2}$ yaş \\
\hline PUFA prevalansı & - & 0 & 0.70 & 1.50 \\
pufa prevalansı & 5.83 & 10.92 & 4.08 & 1.42 \\
Toplam PUFA/pufa prevalansı & 5.83 & 10.92 & 4.78 & 2.92 \\
\hline
\end{tabular}

Büyük harfler daimi dentisyonu, küçük harfler süt dentisyonu göstermektedir; P/p: Pulpa ile ilişkili çürük; U/u: Ülserasyon; F/f: Fistül; A/a: Apse

(\%2.30) daha yüksek olduğu görüldü. Çalışmaya dahil edilen çocuklarda; 6-7 yaş grubunda toplam PUFA/pufa prevalansı en yüksek bulundu (\%10.92). Bunu sırasıyla 5 yaş (\%5.83), 8-10 yaş (\%4.78) ve 11-12 yaş (\%2.92) takip etti.

\section{TARTIȘMA}

Toplumların genel sağlığında olduğu gibi ağız-diş sağlığı düzeylerinin belirlenmesinde ve karşılaştırılabilmesinde de standart göstergeler ve kodlama sistemleri geliştirilmiştir. Son yıllarda yapılan çalışmalar özellikle başlangıç aşamasındaki çürüklerin değerlendirilmesi için daha hassas diagnostik kriterlerin ve yeni indekslerin geliştirilmesi üzerine odaklanmıştır. Gelişmiş ülkelerde koruyucu ve girişimsel olmayan tedaviler öncelik oluşturmakta ve çürüklerin başlangıç aşamasında tespit edilmesine çalışılmaktadır. Ancak gelişmekte olan ve gelişmemiş ülkelerde diş çürüğü yaygın bir hastalık olmaya devam ettiği için tedavi edilmemiş diş çürüklerinin sebep olduğu sonuçların sınıflandırılması için bir indekse gereksinim vardır.

Çocukların ağız sağlığı ile ilgili problemlerinin belirlenmesinde ve saha çalışmalarında genellikle DMFT/dmft indeksi klinik ölçüt olarak alınmaktadır. DSÖ ağız sağlığı ile ilgili hedeflerini DMFT/dmft indeksini kullanarak belirtmektedir. ${ }^{20} \mathrm{Bu}$ indeks ile elde edilen veriler çürük varlığı/yokluğu hakkında bilgi sağlarken; tedavi edilmemiş diş çürüğü sayısının fazlalığı, şiddeti, diş enfeksiyonları ile yaşam kalitesi ve genel sağlıkla ilişkisi hakkında bilgi verememektedir. Aynı şekilde DMFT/dmft indeksinde diş kaybının olup/olmadığı ile ilgili bir skor bulunurken, bu kaybın sebebini bildirememektedir. Bu intiyaçlara yanıt olarak PUFA/pufa indeksi geliştirilmiştir. ${ }^{14} \mathrm{Bu}$ tür verilerden elde edilen sonuçların ciddiyetini daha iyi anlayabilmek için tamamlayıcı bir araç olarak PUFA/pufa indeksinin kullanımı tavsiye edilmektedir. Böylece sağık planlayıcıları ağız sağlığı ile ilgili hedefleri belirlerken $\mathrm{DMFT} / \mathrm{dmft}$ indeksinin yanında tamamlayıcı indeksleri kullanarak daha gerçeği yansıtan sonuçlar elde edebilirler ve tedavi ihtiyaçlarını (diş çekimi, restorasyon, endodontik tedavi) belirlemede kullanabilirler.

Tedavi edilmemiş diş çürüklerinin varlığının, çocuğun ve ailesinin yaşam kalitesini etkileyen en önemli etkenlerden biri olduğu çeşitli çalışmalarda belirtilmiştir. 2,4,7,9,22 Tedavi edilmemiş diş çürükleri ve bunların sonuçlarının (pulpayı içeren kavite, apse, ülserasyon ve fistül gibi) prevalansını araştıran çalışmaların literatürde sınırlı sayıda olduğu görülmektedir. $7,11,14,17,22,23$ Sunulan çalışma ise konuyla ilgili olarak ülkemizde elde edilen ilk değerlerdir. Çalışmada dmft ve DMFT birlikte kullanıldığında 5-12 yaş çocukların alınmasının uygun olduğu belirtildiği için benzer şekilde pufa/PUFA değerlendirmesi için de bu yaş grubu seçilmiştir. ${ }^{5}$

5-12 yaş arasındaki 1200 çocuk üzerinde yürütülen bu çalışmada, daimi dişler için PUFA prevalansı \%2.3 olarak bulunmuştur. Bu değer, Monse ve

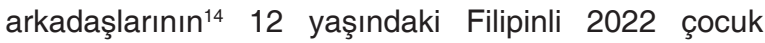
üzerinde yaptıkları çalışmanın PUFA prevalansı ile (\%50), Shanbhog ve arkadaşlarının ${ }^{24} 12-14$ yaş arası 488 Hintli çocuk üzerinde yaptıkları çalışmadaki PUFA prevalansı (\%37.7) ve Murthy ve arkadaşlarının ${ }^{13}$ Hindistan'da 12-15 yaş arasındaki 1452 çocuk üzerinde yaptıkları çalışmadaki PUFA prevalansından (\%14.1) düşük bulunmuştur. Çalışmamızdaki daimi dişler için PUFA prevalans değerinin diğer çalışmalardan düşük bulunmasının nedeninin çalışmamızın yaş popülasyonu ile ilgili olduğu düşünülmektedir. Diğer çalışmalarda yalnızca daimi dentisyondaki hastalar değerlendirilmeye dahil edilirken; bizim çalışmamızda karışık dişlenme dönemindeki hastaların daimi dişleri için PUFA prevalans değerleri hesaplanmıştır.

Yürütülen çalışmada, süt dişleri için toplam pufa prevalansı \%22.25 olarak; bununla birlikte 5 yaşındaki pufa prevalansı $\% 5.83$ olarak, 6-7 yaş pufa prevalansı $\% 10.92$ olarak, $8-10$ yaş pufa prevalansı $\% 4.08$ ve 11-12 yaş pufa prevalansı $\% 1.42$ olarak bulunmuştur. Leal ve ark. ${ }^{7}$ tarafından 6-7 yaşlarındaki 587 Brezilyalı çocukta yapılan çalışmada pufa prevalansı \%26.2; Figueiredo ve ark. ${ }^{22}$ tarafından 6-7 yaş arasındaki 835 çocuk üzerinde yapılan çalışmada \%23.7; Baginska ve ark. ${ }^{11}$ tarafından 5-7 yaş arasında 215 Polonyalı çocuk üzerinde yapılan çalışmada \%59.1 olarak bildirilmiştir. Çalışmamızda bulunan değerler bu çalışmaların sonuçları ile karşılaştırıldığında, pufa prevalans değerlerinin daha düşük olduğu görülmektedir.

Bununla birlikte çeşitli ülkelerde pufa indeksi ile ilgili yapılan çalışmalarda süt dişlerinin pufa prevalansı; Ferraz ve ark. ${ }^{17}$ tarafından Brezilya'da 2-5 yaş arasında 
540 çocukta yapılan çalışmada \%12; Mehta ve Bhalla ${ }^{23}$ tarafından 5-6 yaşlarındaki 603 Hintli çocukta yapılan çalışmada \%38.6; Monse ve arkadaşlarının ${ }^{14} 6$ yaşındaki Filipinli 2030 çocuk üzerinde yaptığı çalışmada ise pufa prevalansının \%84 olduğu bildirilmiştir. Bu çalışmalardaki yaş gruplarının çalışmamızdaki yaş aralıklarından farklı olması nedeni ile karşılaştırılması mümkün olmamıştır.

Bu çalışmada hem süt hem de daimi dişlerde toplam PUFA/pufa prevalansında en yüksek skoru süt dişlerinde (p) \%11.24 ve daimi dişlerde (P) \%1.67 ile pulpayı içeren diş çürüğü oluşturmaktadır. Bunu süt dişlerinde fistül oluşumu, apse ve ülserasyon izlemektedir. Daimi dişlerde ise ülserasyona rastlanmazken, apse ve fistülizasyon aynı oranda gözlenmiştir. Elde edilen veriler diğer çalışmaların sonuçları ile benzerlik göstermektedir. ${ }^{10,11,23,24}$

Süt dişleri 12 yaşına kadar ağız boşluğunda görev aldığı için, bu dişlerin prognozunu değerlendirmek önemlidir. Dünya genelinde süt dişlerinin tedavisi ile ilgili eksiklikler olduğu rapor edilmiştir. ${ }^{8}$ DSÖ temel ağız sağlığı metodolojisinde, süt dişlenmenin sağlığının değerlendirilmesini özellikle tavsiye etmektedir. ${ }^{12}$ Yapılan bu çalışmada süt diş̧lerindeki tedavi edilmemiş diş çürüklerinin prevalansının (\%22.25) daimi dişlerin prevalansından (\%2.30) oldukça yüksek olduğu bulunmuştur. Bunun küçük yaştaki çocukların diş hekimi korkusu kaynaklı tedavilerini yaptırmaması ve/veya ailelerin süt dişlerinin tedavisi konusunda farkındalıklarının az olması sebebi ile olduğu düşünülmektedir. Korku nedeni ile koruyucu ve tedavi edici yaklaşımlar için uzun süre beklenilmesi çürüğün şiddetini arttırmakta ve restorasyon yerine dişin endodontik tedavisi veya çekimini gerektirmektedir. ${ }^{25}$ Ayrıca 12 yaş fizyolojik olarak karışık dişlenmenin henüz bittiği ve daimi dişlenmenin başladığı yaş olması sebebiyle daimi dişlenmedeki düşük oranı göstermektedir.

Diş çürüğü multifaktoriyel bir hastalıktır ve çeşitli sosyal, kültürel ve ekonomik faktörler etiyolojisinde rol oynamaktadır. Bu çalışma geniş bir hasta popülasyonunda yürütüldüğü için ve yukarıdaki faktörler göz önüne alındığında, diş çürüğü prevalansının diğer çalışmaların sonuçlarına göre değişiklik gösterebileceği düşünülmektedir.

$\mathrm{Bu}$ çalışmanın sonucunda belirtildiği gibi popülasyonda çocuklarda tedavi edilmemiş diş çürüklerinin sayısı oldukça yüksektir. Bu yüzden okul öncesi ve okul çağındaki çocuklar için diş çürüğünü önleyici ve tedavi edici programlar acil olarak planlanmalıdır. Ağız sağlığı okul müfredatına ders olarak eklenmeli, aileler ve öğretmenlere verilecek konferanslarla farkındalıklarının artması sağlanmalıdır.

PUFA/pufa indeksi yüksek çürük prevalansı bulunan ülkemizde, tedavi edilmemiş diş çürüklerinin sebep olduğu durumların araştırılmasında kullanılabilecek uygun bir indekstir. Çalışmacılar arasında yüksek seviyede uyum gözlenmesi, indeksi uygulamanın az zaman alması ve ek yardımcı malzeme gerekli olmaması indeksin kullanımı kolay ve güvenilir olmasını sağlamaktadır. PUFA/pufa indeksi, DMFT/dmft indeksi ile birlikte popülasyondaki tedavi edilmemiş diş çürüklerinin sonuçlarının rapor edilmesi için mükemmel bir epidemiyolojik ve eğitici bir indekstir. $\mathrm{Bu}$ popülasyondaki yüksek pufa prevalans değerinin nedenlerini araştırmak için daha fazla yapılacak çalışmaya intiyaç duyulmaktadır.

\section{SonUç}

Seçilen popülasyonda tedavi edilmemiş süt dişi çürüklerinin ve yumuşak dokudaki klinik sonuçlarının prevalansı yüksek bulunmuştur. PUFA/pufa indeksi diş çürüklerini değerlendirmek amacıyla DMFT/dmft indeksini tamamlayıcı bir epidemiyolojik araç olarak görülmektedir.

\section{TEŞEKKür VE ANMA}

Bu çalışma 4-7 Ekim 2012 tarihinde Antalya'da düzenlenen 19. Türk Pedodonti Derneği Kongresinde poster olarak sunulmuştur.

Çıkar çatışması: Yazarlar bu çalışmayla ilgili herhangi bir çıkar çatışmalarının bulunmadığını bildirmişlerdir.

\section{KAYNAKLAR}

1. Antunes JL, Peres MA, de Campos Mello TR, Waldman EA. Multilevel assessment of determinants of dental caries experience in Brazil. Community Dent Oral Epidemiol 2006;34:146-52.

2. Martins-Júnior PA, Oliveira M, Marques LS, Ramos-Jorge ML. Untreated dental caries: impact on quality of life of children of low socioeconomic status. Pediatr Dent 2012;34:49-52.

3. Ashkanank F, Al-Sane M. Knowledge, attitudes and practise of caregivers in relation to oral health of preschool children. Med Princ Pract 2013;22:167-72.

4. Bönecker M, Abanto J, Tello G, Oliveira LB. Impact of dental caries on preschool children's quality of life: an update. Braz Oral Res 2012;26:103-7.

5. Gökalp SG, Doğan BG, Tekçiçek MT, Berberoğlu A, Unlüer S. National survey of oral health status of children and adults in Turkey. Community Dent Health 2010;27:12-7.

6. Filstrup SL, Briskie D, da Fonseca M, Lawrence L, Wandera A, Inglehart MR. Early chilhood caries and quality of life: child and parent perspectives. Pediatr Dent 2003;25:431-40.

7. Leal SC, Bronkhorst EM, Fan M, Frencken JE. Untreated cavitated dentine lesions: impact on children's quality of life. Caries Res 2012;46:102-6.

8. Benzian H, Monse B, Heinrich-Weltzien R, Hobdell M. Untreated severe dental decay: a neglected determinant of flow Body Mass Index in 12-year-old Filipino children. BMC Public Health 2011;11:558.

9. Gradella CM, Bernabé E, Bönecker M, Oliveira LB. Caries prevalence and severity, and quality of life in Brazilian 2- to 4- year-old children. Community Dent Oral Epidemiol 2011;39:498-504.

10. Baginska J, Stokowska W. Pulpal involvement-roots-sepsis index: a new method for describing the clinical consequences of untreated dental caries. Med Princ Pract 2013;22:555-60.

11. Bagińska J, Rodakowska E, Wilczyńska-Borawska M, Jamiołkowski J. Index of clinical consequences of untreated dental caries (pufa) in primary dentition of children from north-east Poland. Adv Med Sci 2013;58:442-7.

12. Leake J, Jozzy S, Uswak G. Severe dental caries, impacts and 
determinants among children 2-6 years of age in Inuvik Region, Northwest Territories, Canada. J Can Dent Assoc 2008;74:519.

13. Murthy AK, Pramila M, Ranganath $S$. Prevalence of clinical consequences of untreated dental caries and its relation to dental fear among 12-15-year-old schoolchildren in Bangalore city, India. Eur Arch Paediatr Dent 2014;15:45-9.

14. Monse $B$, Heinrich-Weltzien $R$, Benzian $H$, Holmgren $C$, van Palenstein Helderman W. PUFA-an index of clinical consequences of untreated dental caries. Community Dent Oral Epidemiol 2010;38:7782.

15. Usha M, Deepak V, Venkat S, Gargi M. Treatment of severely mutilated incisors: a challenge to the pedodontist. J Indian Soc Pedod Prev Dent 2007;25:34-6.

16. Slabsinskiene E, Miciuviene S, Narbutaite J, Vasiliauskiene I, Andruskeviciene V, Bendoraitiene EA, et al. Severe early childhood caries and behavioral risk factors among 3-year-old children in Lithuania. Medicina (Kaunas) 2010;46:135-41.

17. Ferraz NK, Nogueira LC, Pinheiro ML, Marques LS, Ramos-Jorge ML, Ramos-Jorge J. Clinical consequences of untreated dental caries and toothache in preschool children. Pediatr Dent 2014;36:389-92.

18. Alkarim HA, Watt RG, Pikhart H, Sheiham A, Tsakos G. Dental caries and growth in school-age children. Pediatrics 2014;133:616-23.

19. Pinkham JR, Casamassimo PS, Fields WH Jr, Mc Tigue DJ, Novak AJ. Pediatric dentistry: infancy through adolescense, 4th. edn. St.Louis, Missouri: Elsevier Saunders; 2005. p. 69-71.

20. World Health Organization. Oral health surveys: basic methods, 5 th edn. Geneva: WHO Press; 2013.

21. Oziegbe EO, Esan TA. Prevalence and clinical consequences of untreated dental caries using PUFA index in suburban Nigerian school children. Eur Arch Paediatr Dent 2013;14:227-31.

22. Figueiredo MJ, de Amorim RG, Leal SC, Mulder J, Frencken JE. Prevalence and severity of clinical consequences of untreated dentine carious lesions in children from a deprived area of Brazil. Caries Res 2011;45:435-42.

23. Mehta A, Bhalla $S$. Assessing consequences of untreated carious lesions using pufa index among 5-6 years old school children in an urban Indian population. Indian J Dent Res 2014;25:150-3.

24. Shanbhog R, Godhi BS, Nandlal B, Kumar SS, Raju V, Rashmi S. Clinical consequences of untreated dental caries evaluated using PUFA index in orphanage children from India. J Int Oral Health 2013;5:1-9.

25. Armfield JM, Stewart JF, Spencer AJ. The vicious cycle of dental fear: exploring the interplay between oral health, service utilization and dental fear. BMC Oral Health 2007;7:1.

\section{Evaluation of untreated dental caries in children with PUFA index}

\begin{abstract}
OBJEctive: Tooth decay continues to come up as a serious health problem particularly in developing countries. Limited number of studies investigated the prevalence of complication of untreated dental caries as abscess, fistula and ulceration. The purpose of the present study was to investigate the prevalence of the clinical consequences of untreated dental caries among a group of children.
\end{abstract}

Materials and Method: The study was conducted on 1200 children with ages between 5-12 years in the Department of Pedodontics, Faculty of Dentistry, Gazi University between the dates 1-31 March 2012. Caries in deciduous and permanent teeth were scored using DMFT/dmft and PUFA/pufa indexes (D/d: decayed, M/m: missing, F/f: filled, P/p: carious lesion with pulpal involvement, $U / \mathrm{u}$ : ulceration of the mucosa due to root fragments, F/f: fistula, A/a: abscess).

RESULTS: DMFT index was $2.34 \pm 1.37$ and $\mathrm{dmft}$ index was $4.25 \pm 3.46$. The prevalence of PUFA/pufa for permanent and deciduous teeth was $2.30 \%$ and $22.25 \%$, respectively. The highest score in both permanent and deciduous teeth was caries lesions with pulpal involvement (\%11.24 for deciduous teeth and \%1.67 for permanent teeth). This was followed by abscess and fistula formation.

CONCLUSION: The prevalence of clinical consequences of untreated dental caries was high for deciduous teeth in the selected population. The PUFA/pufa index is seen as an epidemiological tool complementary to the existing caries index aimed to assess dental caries.

KEYWORDS: Abscess; child; dental caries; DMF indexes; fistula 